\title{
Open access and its impact on access and subscriptions
}

\author{
Michael Levine-Clark* \\ Dean of Libraries, University of Denver, 2150 E Evans Ave, Denver, CO 80208, USA
}

\begin{abstract}
In this paper the author examines from a library perspective some of the complications with transitioning to an open access model for journal publishing; how costs that support publishing efforts may shift from readers to researchers; what's happening within the library community with regard to assessing the value of subscriptions; and what universities may come to expect from content providers as private funders take a more visible role in mandating the "openness" of research information.
\end{abstract}

Keywords: Open access, scholarly publishing, big deal, article processing charge, business models, subscription models

At the recent NFAIS Annual Conference [1], I was asked to speak about the impact of open access (OA) on academic libraries. I chose to focus on some of the barriers that make it difficult for us to transition from a subscription model to an open future. Open access is undoubtedly a good thing. It makes the published output of scholarly research available to the widest possible audience, making further research and knowledge development possible. Free availability of published research benefits scholars at institutions that cannot afford to subscribe to expensive journal packages ("big deals") or who have no affiliation at all with an institution. The end goal of a truly open scholarly communication system is one that is tremendously appealing, but how we can get there is not entirely clear.

Academic librarians have led the open access movement from the beginning, because OA will lead to the broadest possible access to information - a goal that aligns perfectly with library values - and because OA has the potential to solve pressures that see huge portions of library budgets dedicated to maintaining big deals. Librarians have been exploring models to "flip" subscription-based journals to OA, and a Max Planck Institute study determined that there is enough money in the global subscription system to cover article processing charges (APCs) for all published articles [2]. But when we look at some of the details of these models, it becomes clear that changing the model will not be easy. First, the Big Deal itself is a messy model, inconsistently applied across libraries, so a transition away would likely be equally messy and inconsistent. Second, research output and subscription expenditures do not closely align at all institutions. There are universities with relatively high research output and low subscription expenditures and vice versa, so a transition model that assumes a switch from subscription to an Article Processing Charge (APC) business model would be difficult.

Let's look at the big deal first. This is a model in which libraries have negotiated with a publisher for access to most or all of that publisher's journal content for a heavily discounted price, but at the expense of

*E-mail: michael.levine-clark@du.edu.

0167-5265/18/\$35.00 @ 2018 - IOS Press and the authors.

This article is published online with Open Access and distributed under the terms of the Creative Commons Attribution Non-Commercial License (CC BY-NC 4.0). 
locking in a continuing commitment to pay that publisher. Big Deals are generally based on the library's spending level with that publisher at the point when it transitioned from print to digital subscriptions. The library agrees to continue paying that amount plus an increase for inflation annually and the publisher agrees to provide access to far more than the titles that are nominally subscribed. These deals are often negotiated at the consortium level, and they usually allow the institution to provide access to a bigger pool of titles than would be possible with a title-by-title subscription model. There is little transparency in how these deals are constructed, and it is very hard to understand the cost at the journal level (and even harder at the article level). If a library is paying for some "subscribed" titles and another amount for access to the "unsubscribed" titles, then it is hard to consider how to convert subscription costs for a Big Deal to payment costs toward conversion to Open Access. And that is made harder still by the fact that the shares of the costs are unevenly borne across the consortium.

We tend to measure the value of the Big Deal in terms of cost-per-use, but this is a flawed model. Cost-per-use assumes that all use is good use, but perhaps use of many articles is a sign of inefficiency. Increased choice (more content available) may mean more use, but perhaps it also means less critical use, since users confronted with an abundance of content "use" articles to determine what is not relevant. As long as we assume that use is the way to measure value, it's very hard to move beyond subscriptions. It is time for a new model: value linked to outcomes. A model of this sort might make it easier to cancel the Big Deal and transition to paying for Open Access. Transitioning our subscription expenditures to a new model is hard enough without fully understanding the value of usage.

The structure of the Big Deal itself causes difficulties in pondering a transition. If you imagine a typical Big Deal of one thousand titles managed across a consortium, you have libraries with different subscription bases - one might subscribe to one hundred titles and pay a fee for access to nine hundred. Another might subscribe to five hundred titles and pay a fee for access to the other five hundred. And a third might subscribe to twenty journals and pay a fee for access to nine hundred and eighty titles. All have access to the same titles for their users, but pay radically different amounts. Now imagine that some of the titles in that mix are hybrid journals, with varying amounts of content made open by an author paying an Article Processing Charge (APC). And imagine that some of these journals become fully open. If these open or partially-open titles are part of a library's subscription list, then it is possible to calculate some sort of decrease to the subscription cost, but if something becomes open and is part of the unsubscribed (access) list then the potential discount is negligible. This is made even more complicated if the authors at these three institutions have paid APCs to make some of these articles open. If a newly-open journal is part of the subscribed list at one of these institutions, but on an unsubscribed list at the other two, then the overall impact on the consortia deal is even harder to measure.

How easy is it to transition to Open Access? Funding for APCs tends to come from the institution in conjunction with the grants awarded to that institution's researchers. But there is a very uneven distribution of publishing outputs and subscription costs from university to university. Take the University of Denver (DU) and California Institute of Technology (Cal Tech) for example. In 2016, Web of Science indicated that $\mathrm{Cal}$ Tech scholars published thirty-seven hundred articles. Since we know that many articles are not indexed in this source, we can add in about $25 \%$ more articles, giving us a total of forty-nine hundred. Assuming that $60 \%$ of these articles had a Cal Tech scholar as corresponding author that now reduces the total to two thousand nine hundred and sixty articles. At a conservative $\$ 2,500$ per APC, Cal Tech would have had to spend $\$ 7.5$ million on publication costs. In 2016, though, Cal Tech spent $\$ 3.1$ million on continuing resources. Their subscription costs are far lower than their publication costs would ever be, and even if half of their APCs were covered by external funding, they would come up short. The Pay 
it Forward study from the California Digital Library and University of California, Davis demonstrates clearly that most other high-research institutions would experience similar effects [3].

Meanwhile the University of Denver accounted for seven hundred articles in 2016 in Web of Science. Using the same logic, adding $25 \%$ brings us up to a total of eight hundred seventy five. Assuming $60 \%$ come from corresponding authors, the figure is reduced to five hundred and twenty-five articles. At an APC of \$2,500 per article DU would spend \$1.3 million on publication costs. Meanwhile DU's budget for continuing resources in 2016 was $\$ 4.1$ million. Clearly DU, as a net consumer of information, would come out ahead in a transition away from a subscription model while $\mathrm{Cal}$ Tech, as a net producer of information, would have to come up with new funds.

These are both research institutions, though with quite different profiles. What about a smaller institution without a research mission? While it is appealing to assume that a small teaching-focused school could participate in a transition to OA, it seems more likely that such a school would be tempted to become a free rider, using the necessary expenditures of research institutions to gain access to published content, but not covering the costs of publication for its own faculty - for whom research is secondary.

This is just a brief investigation of some of the complications inherent in a transition from a subscription model to open access in North America. The tremendous disparity of research output across institutions combined with the wide range of expenses for subscriptions and the variance in how Big Deals are constructed means that it will be tremendously difficult to affect such a transition. I hope it happens, but I'm not optimistic about it being an easy process.

\section{About the Author}

Michael Levine-Clark is the Dean of the University of Denver Libraries. He writes and speaks regularly on trends relating to academic library content management, discovery, and scholarly communication. Email: michael.levine-clark@du.edu.

\section{References}

[1] National Federation of Advanced Information Services (NFAIS), 2018 Annual Conference, Information Transformation: Open, Global, Collaborative, February 28 - March 2, 2018, Alexandria, VA, USA (see: http://www.nfais.org/2018conference-program. Last accessed 14 June 2018).

[2] R. Schimmer, K.K. Geschuhn and A. Vogler, Disrupting the Subscription Journal's Business Model for the Necessary Large-Scale Transformation to Open Access, a Max Planck Digital Library Open Access White Paper, 28 April 2015, http://pubman.mpdl.mpg.de/pubman/item/escidoc:2148961:7/component/escidoc:2149096/MPDL_OATransition_White_Paper.pdf, last accessed 14 June 2018.

[3] University of California Libraries, Pay it Forward: Investigating a Sustainable Model of Open Access Article Processing Charges for Large North American Research Institutions, Funded by the Mellon Foundation, 30 June 2016, revised 18 July 2016, http://icis.ucdavis.edu/wp-content/uploads/2016/07/UC-Pay-It-Forward-Final-Report.rev_.7.18.16.pdf. Last accessed 14 June 2018. 